\title{
Increased levels of sodium chloride directly increase osteoclastic differentiation and resorption in mice and men
}

\author{
L. Wu ${ }^{1,2}$ - B. J. C. Luthringer ${ }^{1}$ F. Feyerabend ${ }^{1}$ - Z. Zhang ${ }^{2,3} \cdot$ H. G. Machens ${ }^{2}$ • \\ M. Maeda ${ }^{4}$ H. Taipaleenmäki ${ }^{4}$ E. Hesse ${ }^{4}$ R. Willumeit-Römer ${ }^{1}$ - A. F. Schilling ${ }^{2,5}$
}

Received: 20 February 2017 / Accepted: 13 July 2017 /Published online: 29 August 2017

(C) The Author(s) 2017. This article is an open access publication

\begin{abstract}
Summary To better understand the association between high salt intake and osteoporosis, we investigated the effect of sodium chloride $(\mathrm{NaCl})$ on mice and human osteoclastogenesis. The results suggest a direct, activating role of $\mathrm{NaCl}$ supplementation on bone resorption.

Introduction High $\mathrm{NaCl}$ intake is associated with increased urinary calcium elimination and parathyroid hormone (PTH) secretion which in turn stimulates the release of calcium from the bone, resulting in increased bone resorption. However, while calciuria after $\mathrm{NaCl}$ loading could be shown repeatedly, several studies failed to reveal a significant increase in PTH in response to a high-sodium diet. Another possible explanation that we investigated here could be a direct effect of highsodium concentration on bone resorption.

Methods Mouse bone marrow macrophage and human peripheral blood mononuclear cells (PBMC) driven towards an osteoclastogenesis pathway were cultivated under culture conditions mimicking hypernatremia environments.
\end{abstract}

A. F. Schilling

arndt.schilling@med.uni-goettingen.de

1 Department of Biological Characterisation, Institute for Materials Research, Helmholtz-Zentrum Geesthacht, Geesthacht, Germany

2 Department of Plastic Surgery and Hand Surgery, Klinikum Rechts der Isar, Technical University Munich, Munich, Germany

3 Department of Orthopedics, Hand Surgery Division, Tongji Hospital, Tongji Medical College, Huazhong University of Science and Technology, Wuhan, Hubei, People's Republic of China

4 Heisenberg Group for Molecular Skeletal Biology, Department of Trauma, Hand, and Reconstructive Surgery, University Medical Center Hamburg-Eppendorf, Hamburg, Germany

5 Clinic for Trauma Surgery, Orthopedic Surgery, and Plastic Surgery, University Medical Center Göttingen, Göttingen, Germany
Results In this study, a direct effect of increased $\mathrm{NaCl}$ concentrations on mouse osteoclast differentiation and function was observed. Surprisingly, in a human osteoclast culture system, significant increases in the number of tartrate-resistant acid phosphatase (TRAP)-positive osteoclasts, calcitonin receptor (CTR)-positive osteoclasts, nuclear factor-activated T cells $\mathrm{c} 1$ (NFATc1) gene expression, and areal and volumetric resorptions were observed for increasing concentrations of $\mathrm{NaCl}$. This suggests a direct, activating, cell-mediated effect of increased concentrations of $\mathrm{NaCl}$ on osteoclasts.

Conclusions The reported that enhanced bone resorption after high-sodium diets may not only be secondary to the urinary calcium loss but may also be a direct, cell-mediated effect on osteoclastic resorption. These findings allow us to suggest an explanation for the clinical findings independent of a PTHmediated regulation.

Keywords Hypernatremia $\cdot \mathrm{NaCl} \cdot$ Osteoclasts $\cdot$ Osteoporosis $\cdot$ Resorption

\section{Introduction}

Osteoporosis is a progressive skeletal disease characterized by a decrease in bone mass and a disruption of bone architecture, leading to enhanced bone fragility and consequent increase in fracture risk especially in the elderly [1]. This disease has become a highly prevalent health problem that affects millions of people around the world due to the increased longevity of the population, which results in it being a leading cause of disability and even premature death. Although generally regarded as a disease that predominantly affects women, it is estimated that approximately $30 \%$ of osteoporotic hip fractures occur in men. Due to the steady increase in the proportion of the elderly population and the rise in the incidence of 
fractures at earlier ages, an estimated doubling in the direct costs of such fractures to the healthcare services in the European Union (EU) is predicted by 2050 [2].

Bone density in later life mainly depends on two key determinants: the peak bone mass achieved at skeletal maturity (during the third decade of life) and subsequent decline in bone strength and density occurring with age [3]. The peak bone density is strongly determined by genetic factors (accounting for $60-80 \%$ of the variance) and other secondary factors such as nutrition, hormones, environment, and lifestyle [4]. Calcium, potassium, magnesium, zinc, vitamin C, fiber, and fruits have been reported to induce changes in bone resorption and bone mass [5].

Sodium ion $\left(\mathrm{Na}^{+}\right)$is the predominant cation of the extracellular fluid compartment. It induces the movement of water across cell membranes and largely dictates serum osmolality. Abnormality of sodium concentration due to disorders of water balance can lead to hyponatremia (defined as serum $\mathrm{Na}^{+}$ concentration less than $135 \mathrm{mM}$ ) or hypernatremia (more than $145 \mathrm{mM}$ ). The relationship between $\mathrm{Na}^{+}$and bone density is therefore an evolving field of interest. While hyponatremia has been shown to stimulate osteoclast differentiation and resorptive activity [6] and is thus highly associated with osteoporosis, increased fracture, and fall risks [7], the relationship between hypernatremia and osteoclastogenesis is still open to discussion. Furthermore, although the recommended dietary intake (RDI) for $\mathrm{Na}^{+}$lies between 920 and $2300 \mathrm{mg} /$ day (40$100 \mathrm{mmol} /$ day) [8], there is an inclination for high-salt diets in our society and $\mathrm{Na}^{+}$intake for adults estimated from 24-h urinary excretion to be higher than recommended [8].

Previously published evidences from animal, clinical, and epidemiological studies have highlighted the contribution of high salt intake on osteoporosis development [8, 9]. Dietary sodium chloride $(\mathrm{NaCl})$ supplementation in growing rats elevated the urinary calcium and phosphorus excretions without increasing calcium intestinal absorption, leading to imbalance and decreased accumulation of these minerals in the bone [10]. Research involving postmenopausal women has indicated that after a restricted $\mathrm{Na}^{+}$diet, a decrease in urinary $\mathrm{Na}^{+}$, calcium, and hydroxyproline/creatinine can be observed [11]. On the other hand, evidence derived from humans and rats suggests that high $\mathrm{Na}^{+}$intake is associated with increased urinary excretion of hydroxyproline $[12,13]$. Devine et al. [8] showed a negative correlation between urinary $\mathrm{Na}^{+}$excretion and changes in bone mass over 2 years at the hip and ankle in postmenopausal women in a long-term observational study. In an extensive literature survey, MacGregor concluded that a reduction in salt intake could have a major beneficial role in bone density and therefore the prevention and treatment of osteoporosis [14]. In an interventional study, Lin et al. [15] demonstrated the beneficial effects on bone health caused by a reduction in $\mathrm{Na}^{+}$intake. Harrington [9], in an observational study, also concluded that higher salt intake leads to greater rates of bone resorption in postmenopausal women over a 4-week period.

Already, in 1937, Aub et al. [16] observed that the elevation of $\mathrm{NaCl}$ intake increased the excretion of urine calcium. These findings have been confirmed in numerous animal experiments [17] and in human studies [18]. The extracellular ionized calcium levels are tightly regulated by a complex interrelationship between gastrointestinal calcium absorption, renal excretion, and bone turnover [19]. The average loss of calcium is $1 \mathrm{mmol}$ calcium (40 $\mathrm{mg}$ ) per $100 \mathrm{mmol}$ (2290 mg) of $\mathrm{Na}^{+}$, and without any adaptive compensatory mechanisms, a daily loss of 40-mg calcium would deplete $10 \%$ of the skeleton within a decade [20]. The mode of action, how $\mathrm{NaCl}$ influences bone resorption, is still controversial. Some studies indicated that the increase in urinary calcium excretion is associated with the enhanced production of serum parathyroid hormone (PTH). Goulding et al. found an increase in serum PTH due to high dietary salt loading [21]. In one study conducted by Breslau [22], young adults were also found to respond to $\mathrm{Na}^{+}$supplementation with increases in urinary calcium and serum PTH. Loss of calcium usually triggers excretion of PTH from the parathyroid glands to compensate for it [23]. Therefore, it has been hypothesized that PTH elevation is responsible for an elevated bone resorption in this setting. While an increased resorption of the bone after $\mathrm{NaCl}$ loading could indeed be demonstrated in patients, a significant elevation of PTH could not be measured $[8,20]$.

Therefore, we hypothesized that there may be a direct, cellmediated effect of hypernatremia on bone resorption. To test this hypothesis in vitro, different hypernatremia conditions (normal, mild, moderate, and severe hypernatremia) were modeled by the external addition of $\mathrm{NaCl}$ solution to the cell culture media. The effect of these different hypernatremia conditions on mice and human osteoclast differentiation and function was studied.

\section{Materials and methods}

\section{Cell culture}

Alpha minimum essential medium ( $\alpha$-MEM, Biochrom AG, Berlin, Germany) supplemented with $10 \%(v / v)$ fetal bovine serum (FBS; PAA Laboratories GmbH, Linz, Austria) was used for the preparation of hypernatremia cell culture media. According to the manufacturer's formulation, the basal concentration of $\mathrm{Na}^{+}$is $142 \mathrm{mM}$. A 1-M NaCl (Sigma-Aldrich Chemie GmbH, Munich, Germany) solution was prepared in double-distilled water $\left(\mathrm{ddH}_{2} \mathrm{O}\right)$ and sterile-filtered before being diluted in the cell culture media (final concentrations 0,2 , $5,10,15,25$, and $50 \mathrm{mM}$ ). To characterize the culture media supplemented with different concentrations of $\mathrm{NaCl}$, their $\mathrm{pH}$ and osmolality were determined via an ArgusX $\mathrm{pH}$ meter 
(Sentron Europe BV, Roden, Netherlands) and a Gonotec 030D cryoscopic osmometer (Gonotec, Berlin, Germany), respectively. The results are presented in Table 1. Based on the clinical practice guideline [24], these concentrations were grouped in four categories: normal $(135-145 \mathrm{mM}$; two $\mathrm{NaCl}$ treatment groups obtained by the external addition of 0 and $2 \mathrm{mM} \mathrm{NaCl}$ plus the basal $142 \mathrm{mM} \mathrm{NaCl}$ in $\alpha$-MEM), mild (146-149 mM; one $\mathrm{NaCl}$ treatment group obtained by the external addition of $5 \mathrm{mM} \mathrm{NaCl}$ plus the basal $142 \mathrm{mM}$ $\mathrm{NaCl}$ in $\alpha$-MEM), moderate $(150-169 \mathrm{mM}$; three $\mathrm{NaCl}$ treatment groups obtained by the external addition of 10,15 , and $25 \mathrm{mM} \mathrm{NaCl}$ plus the basal $142 \mathrm{mM} \mathrm{NaCl}$ in $\alpha$-MEM), and severe hypernatremia ( $\geq 170 \mathrm{mM}$; one $\mathrm{NaCl}$ treatment group obtained by the external addition of $50 \mathrm{mM} \mathrm{NaCl}$ plus the basal $142 \mathrm{mM} \mathrm{NaCl}$ in $\alpha$-MEM).

Bone marrow macrophages were flushed from 8 -week-old mice, placed in a $6-\mathrm{cm}^{2}$ dish in $\alpha$-MEM (Biochrom $\mathrm{AG}$, Berlin, Germany), and incubated for $3 \mathrm{~h}$ at $37^{\circ} \mathrm{C}$. After incubation, non-adherent cells were transferred in a $10-\mathrm{cm}^{2}$ dish in the presence of $100 \mathrm{ng} / \mathrm{mL}$ of macrophage colony-stimulating factor (M-CSF; Peprotech Germany, Hamburg, Germany) for 2-4 days. Cells were then counted and seeded in a 96-well plate at a density of 15,000 cells/well in the medium containing $25 \mathrm{ng} / \mathrm{mL}$ of M-CSF (Peprotech Germany, Hamburg, Germany) and $100 \mathrm{ng} / \mathrm{mL}$ of receptor activator of nuclear factor kB ligand (RANKL; Peprotech Germany, Hamburg, Germany) as well as different concentrations of $\mathrm{NaCl}$. The medium was refreshed every 2 days, and the cultures were kept for 11 days to obtain the mature mouse osteoclasts. The effect of different hypernatremia conditions on mouse osteoclast formation was evaluated through tartrate-resistant acid phosphatase (TRAP) activity at days 3, 4, 7, 9, and 11 . TRAP staining was performed on day 4 while their resorption activity was investigated on day 11 .

Buffy coats were obtained from healthy, anonymized donors at the Institute for Clinical Transfusion Medicine and Immunogenesis Ulm, Ulm, Germany, in a procedure approved by the review board of the German National Advisory Committee Blood at the Robert Koch Institute. All donors provided written consent that their cells can be used for medical, scientific, and pharmaceutical purposes. The peripheral blood mononuclear cells (PBMC) were freshly isolated from the buffy coats using a density gradient centrifugation technique. The monocytes were seeded in 48 -well plates at a density of $2 \times 10^{6}$ cells $/ \mathrm{mL}$ and cultured in $\alpha$-MEM (Biochrom AG, Berlin, Germany) containing 10\% (v/v) FBS (PAA Laboratories $\mathrm{GmbH}$, Linz, Austria) with $40 \mathrm{ng} / \mathrm{mL}$ RANKL and $20 \mathrm{ng} / \mathrm{mL}$ M-CSF in the presence of different concentrations of $\mathrm{NaCl}$ for 28 days to allow the complete differentiation and activation of mature osteoclasts. The more detailed protocol can be found in this publication [25]. The impact of different hypernatremia conditions on osteoclastogenesis was measured via cell viability/proliferation and total
Table 1 Characterization of the culture media supplemented with different concentrations of $\mathrm{NaCl}$

\begin{tabular}{lll}
\hline Medium & $\mathrm{pH}$ & $\begin{array}{l}\text { Osmolality } \\
(\mathrm{mOsm} / \mathrm{kg})\end{array}$ \\
\hline a-MEM + 10\%FBS & 7.85 & 330 \\
a-MEM + 10\%FBS + 2 mM NaCl & 7.83 & 334 \\
a-MEM + 10\%FBS + 5 mM NaCl & 7.84 & 340 \\
a-MEM + 10\%FBS + 10 mM NaCl & 7.85 & 350 \\
a-MEM + 10\%FBS + 15 mM NaCl & 7.85 & 360 \\
a-MEM + 10\%FBS + 25 mM NaCl & 7.85 & 380 \\
a-MEM + 10\%FBS + 50 mM NaCl & 7.83 & 430 \\
\hline
\end{tabular}

protein content at days 3, 7, 14, 21, and 28. Furthermore, TRAP staining, calcitonin receptor (CTR) and cathepsin K (CK) immunocytochemistry, resorption activity assay, and real-time PCR were performed at day 28.

\section{Cell metabolism assay}

A water-soluble tetrazolium (WST-1) assay was selected to estimate the effects of various hypernatremia conditions on human osteoclast precursor and osteoclast-like cell (OCL) viabilities according to the manufacturer's instructions (Roche Diagnostic GmbH, Mannheim, Germany). After 3, 7, 14, 21, and 28 days, the cells were subsequently incubated with $50 \mu \mathrm{L} /$ well of WST- 1 dye solution at $37^{\circ} \mathrm{C}$ for $2 \mathrm{~h}$ (biological replicates $n=3$ wells). Culture medium containing $10 \%(v / v)$ of WST-1 without any cells was performed as blank. Following incubation, the supernatant was collected and pipetted into 96-well plates (three technical replicates) and the absorbance was immediately measured with a spectrophotometer at $450 \mathrm{~nm}$ (620-nm reference; Berthold Technologies GmbH, Bad Herrenalb, Germany).

\section{Cell lysate preparation and determination of total protein content}

Total cellular proteins from human osteoclast cultures were extracted by using radioimmunoprecipitation assay (RIPA) lysis buffer (three biological replicates per $\mathrm{NaCl}$ concentration). In order to avoid any sample degradation, all solutions and materials used for this procedure were previously cooled. Cell layers were rinsed twice with PBS and then covered with RIPA lysis buffer which has been supplemented with protease inhibitor cocktail (Sigma-Aldrich Chemie GmbH, Munich, Germany) freshly before use. The adherent cells (including the combination of osteoclast precursors and OCLs) were harvested with a plastic cell scraper. Cell suspensions were subsequently transferred into pre-labeled $1.5-\mathrm{mL}$ microcentrifuge tubes using pipette tips and then maintained on ice for $30 \mathrm{~min}$ 
for lysis with pipetting up and down every $10 \mathrm{~min}$. Lysates were cleared of cell debris by centrifugation at $10,000 \times g$ for $10 \mathrm{~min}$ at $4{ }^{\circ} \mathrm{C}$. The protein content was directly quantified with the BCA Protein Assay Kit $(n=2$; Thermo Fisher Scientific, Bonn, Germany) according to the manufacturing method.

\section{TRAP staining}

To confirm the generation of multinucleated OCLs, the expression of TRAP of the adherent cells on dentin slices was examined cytochemically after 4 days (for mouse) and 28 days (for human) (triplicates for each $\mathrm{NaCl}$ concentration). Adherent cells were rinsed with PBS and fixed with a TRAP fixation solution containing $3.7 \%$ formaldehyde (Carl Roth GmbH, Karlsruhe, Germany) and 0.2\% Triton X-100 (Carl Roth GmbH, Karlsruhe, Germany) at room temperature (RT) for $5 \mathrm{~min}$. Subsequently, fixed cells were dyed for acid phosphatase for $10-20 \mathrm{~min}$ at $37{ }^{\circ} \mathrm{C}$ with $0.1 \mathrm{mg} / \mathrm{mL}$ naphthol AS-MX phosphate (Sigma-Aldrich Chemie GmbH, Munich, Germany) and $0.5 \mathrm{mg} / \mathrm{mL}$ fast red-violet LB salt (Sigma-Aldrich Chemie GmbH, Munich, Germany) in the presence of $10 \mathrm{mM}$ sodium tartrate (Carl Roth GmbH, Karlsruhe, Germany) and $40 \mathrm{mM}$ sodium acetate $(\mathrm{pH}=5$; Carl Roth $\mathrm{GmbH}$, Karlsruhe, Germany) which were freshly prepared before use. The staining solution was then removed and replaced with PBS. Red-stained TRAP-positive multinucleated cells that possessed three or more nuclei were counted as OCLs and photographed. The number of positive cells per square millimeter (at least five representative fields of view per condition) was computed based on the internal calibration of the microscope software (Zeiss).

\section{CTR and CK immunocytochemistry}

The locations of CTR and CK in cultured human osteoclasts were detected by performing immunofluorescence staining and subsequent confocal laser scanning microscopy at day 28. PBS-rinsed cells were fixed by $3.7 \%$ formaldehyde (Carl Roth $\mathrm{GmbH}$, Karlsruhe, Germany) for $10 \mathrm{~min}$ at RT. For CK staining, the fixed cells were subsequently permeabilized with a solution containing $0.1 \%$ Triton X-100 (Carl Roth GmbH, Karlsruhe, Germany) and 3\% hydrogen peroxide $\left(\mathrm{H}_{2} \mathrm{O}_{2}\right), 1: 1$ ( $v / v$; Carl Roth GmbH, Karlsruhe, Germany). Blocking of non-specific binding was performed by immersing the cells in $10 \%(w / v)$ BSA (Carl Roth GmbH, Karlsruhe, Germany) in PBS for $1 \mathrm{~h}$ at $37^{\circ} \mathrm{C}$; thereafter, the cells were incubated with a polyclonal anti-CTR or polyclonal anti-CK primary $\operatorname{IgG~} \mathrm{Ab}$ ( $1: 450$ in PBS containing 1\% $(w / v)$ BSA; Santa Cruz Biotechnology, Inc., Heidelberg, Germany) for $1 \mathrm{~h}$ at $37{ }^{\circ} \mathrm{C}$. After two 5-min PBS washing steps, fluorescence-labeled secondary antibodies (goat anti-rabbit IgG-Texas Red, Santa
Cruz Biotechnology, Inc., Heidelberg, Germany) and Alexa Fluor568 goat anti-rabbit IgG (Life Technologies GmbH, Karlsruhe, Germany) for the anti-CTR and anti-CK primary antibodies, respectively, 1:450, in PBS containing $1 \%(w / v)$ BSA were applied and incubated for $1 \mathrm{~h}$ at $37^{\circ} \mathrm{C}$ without light. Nuclei were counterstained by $1.5 \mu \mathrm{g} / \mathrm{mL}$ 4-6-diamidino- 2 phenylindole (DAPI; Sigma-Aldrich Chemie GmbH, Munich, Germany). For quantification, the means of the percentages of CTR- and CK-positive cells (red-stained cells containing at least three nuclei) in the different culture conditions were further calculated (at least five representative fields of view per condition).

\section{Resorption assay}

Osteoclast activities in both mouse and human culture systems were determined by a lacunar resorption assay in which the surface of the ivory slices (obtained from German customs, in accordance with the international laws for the protection of species; at least three chips per condition) was stained with a $1 \%$ toluidine blue (Carl Roth GmbH, Karlsruhe, Germany) solution (in $\mathrm{ddH}_{2} \mathrm{O}$ ) at day 28. Two-dimensional (2D) and three-dimensional (3D) quantitative evaluations were then performed. Five fields of view of each dentin slice were randomly acquired. For the 2D evaluation, micrographs were acquired and the area of resorption pit was quantified using ImageJ analysis software. The means of the percentages of resorption area relative to the total area of the dentin surface in the different culture conditions were calculated (at least five representative fields of view per condition). Then, the surfaces of the dentin slices were analyzed with a Color 3D laser microscope (VK-9700; Keyence Corp, Japan) equipped with an optical laser unit and a scanning unit. Using VK Analyzer image analyzing software (version VK-X100/X200), 3D micrographs were reconstructed and the resorption volume was calculated (at least five representative fields of view per condition).

\section{Reverse transcription RT-PCR}

RNA extractions were performed at day 28 using High Pure RNA Isolation Kit (Roche, Diagnostic GmbH, Mannheim, Germany) (three biological replicates per $\mathrm{NaCl}$ concentration). RNA concentrations (optical density-OD-at $260 \mathrm{~nm}$ ) and purities (OD260/280) were measured by a NanoDrop 2000c (Thermo Scientific, Bonn, Germany) and converted into complementary DNA (cDNA) using Oligo$\mathrm{dT}$ primers according to the manufacturer's instructions (QuantiTect Reverse Transcription Kit, Qiagen). The resultant cDNA was then subjected to PCR analysis (technical replicates) using SsoFast EvaGreen Supermixes, CFX96 realtime PCR detection system (both from Bio-Rad Laboratories $\mathrm{GmbH}$, Munich, Germany), and the following primers (the 
gene-specific primers and reference genes): 5'-TCTC TCGGCGTTTAATTTGGG, 3'-AACCACCTCTTCAC TGGTCAT for $C K ; 5^{\prime}$-CACCAAAGTCCTGGAGATCC CA, 3'-TTCTTCCTCCCGATGTCCGTCT for nuclear factor-activated T cells c1 (NFATC 1$) ; 5^{\prime}$-CTGG AAGCACGAATGACAGA, 3'-CCTTCTGCTTGCAA ATAGGC for nuclear factor- $\mathrm{kB} 1(N F \kappa B 1)$; 5'-CCCC AGCTTCATACCACCCTA, 3'-CCGGCATCTCAAGG TCACG for the osteoclast-associated receptor $(O S C A R)$; 5'GCTCAACAA GGACACA GTGT GC, 3'- C GCA TCGGATTTCTCTGTCCCA for the receptor activator of nuclear factor $\mathrm{KB}(R A N K)$; 5'-ATGGAAGGGTTTCCCCTCGT, 3'-CCAGTAATGGTCGCTATGGCT for spleen focusforming virus (SFFV) proviral integration oncogene (SPI1); 5'-CTTCCTGGGCATGGAGTC, 3'-TGATCTTCATTGTG CTGGGT for Actin $\beta$; 5'-TGCTGTCTCCATGTTTGATG TATCT, 3'-TCTCTGCTCCCCACCTCTAAGT for beta-2microglobulin (B2M); 5'-GTCGGAGTCAACGGATTTG, 3'-TGGGTGGAATCATATTGGAA for glyceraldehyde-3phosphate dehydrogenase (GAPDH), and 5'-AGTG GATGAGTTTCCGCTTT, 3'-ATATGGAAGCCATC TTTGCC for ribosomal protein L10 (RPL10). Reference genes (actin $\beta, B 2 M, G A P D H$, and RPL10) were carefully selected based on the geNorm algorithm method automatically calculated with the CFX Manager software. As the mispriming products and primer-dimers can complicate data interpretation, a melt curve analysis was performed to ensure the specificity of the PCR amplification. No-template control (NTC) melt curves are also conducted for evaluating specificity. Only the specific amplification (a single, tight peak on the dissociation curve for each well on the real-time PCR plate) was used for further analysis. Expression of the markers was normalized to the expression of the housekeeping genes, and results were analyzed with CFX Manager Software (Bio-Rad, Munich, Germany; version 3.1). Different gene expressions were statistically analyzed with a volcano plot in which the regulation threshold and $p$ value were set to 2.00 and 0.05 , respectively.

\section{Statistical analysis}

The entire experiment was carried out independently in two donors. One-way analysis of variance (ANOVA) was employed to assess the statistical significance of results via SigmaStat package (Systat software GmbH, Erkrath, Germany; version 11.0). The probability of a type I error was set to $5 \%$ (alpha $=0.05$ ). The error bars represent standard deviation (SD). Linear regression analysis was performed with the change in TRAP-positive staining counts and 2D and $3 \mathrm{D}$ resorption activities as the dependent variables and supplemented $\mathrm{NaCl}$ concentration as the independent variable via SPSS Statistics version 20.

\section{Results}

\section{Effects of increased $\mathrm{NaCl}$ concentrations} on the differentiation and function of mouse osteoclasts

The TRAP staining and resorption activities of mouse osteoclasts cultured in different hypernatremia conditions were investigated, and the results are shown in Fig. 1a, b, respectively. While the $50 \%$ increase in TRAP-positive cell numbers under moderate hypernatremia conditions was not statistically significant, resorptive activity was significantly higher in the moderate hypernatremia condition, consistent with the activating effect of $\mathrm{NaCl}$ at this concentration. Under the severe hypernatremia condition, the formation of TRAP-positive OCLs and their resorption activities were significantly reduced compared to the control, suggesting a potential toxic effect of very high concentrations of $\mathrm{NaCl}$ on murine osteoclasts.

\section{Cell metabolism assay}

To study the influence of increased $\mathrm{NaCl}$ concentrations on the cell metabolism of human PBMC driven towards osteoclastogenesis, WST-1 assay was performed on days 3, 7, 14, 21, and 28 (Fig. 1c). A bell-shaped pattern was observable with the maximum at mild hypernatremia condition on day 3 (statistically significant difference detected between normal and mild/moderate conditions) and moderate hypernatremia condition on days $7,14,21$, and 28 (statistically significant difference detected between normal and moderate conditions on day 14).

\section{Cell lysate preparation and determination of total protein content}

The total protein contents of human cells cultured in the media supplemented with various hypernatremia conditions were measured after $3,7,14,21$, and 28 days of culture. Here, a decrease in the severe condition could be observed compared to other conditions (Fig. 1d). Significant differences were detected between the severe and normal conditions on day 3 and day 7. It is noteworthy that total protein contents were always the lowest in the case of severe hypernatremia at each time point.

\section{TRAP staining}

The increasing of $\mathrm{NaCl}$ concentrations led to increasing numbers of human TRAP-positive osteoclasts (Fig. 2a). It was observed that the severe hypernatremia condition throughout the 28-day incubation significantly enhanced the formation of TRAP-positive OCLs (approximately fourfold increase when compared to the normal condition; Fig. 2b). Significant 
Fig. 1 The effects of different concentrations of $\mathrm{NaCl}$ on mouse osteoclast differentiation and function were assessed by TRAP (a) and resorption activity (b). The effects of $\mathrm{NaCl}$ on human osteoclast precursors and OCL viability were assessed by WST-1 assay (c). For each time point, three wells of cell supernatant in each $\mathrm{NaCl}$ condition were conducted and measured with a spectrophotometer (technical triplicate). Total protein content isolated from human cells cultured with serial concentrations of $\mathrm{NaCl}$ at days $3,7,14,21$, and 28 (d). For each time point, total cellular proteins were isolated (triplicates per $\mathrm{NaCl}$ condition), and their content was quantified (two technical replicates). The respective statistical analyses are presented, and symbols represent the statistical significances between each group $(p<0.05)$ a
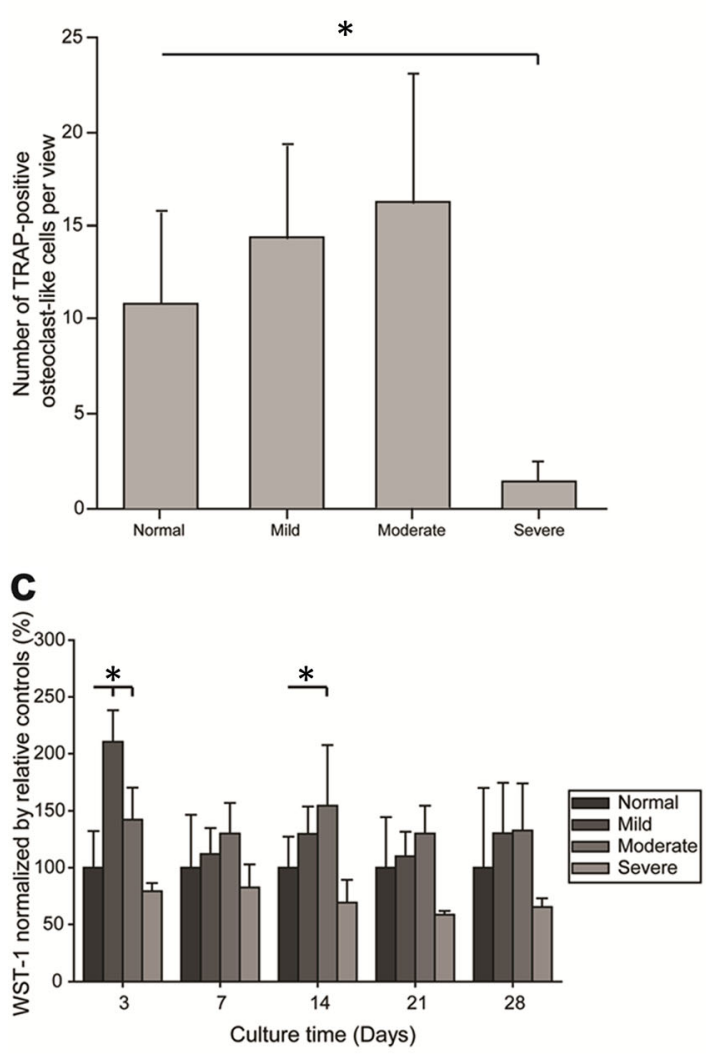

b

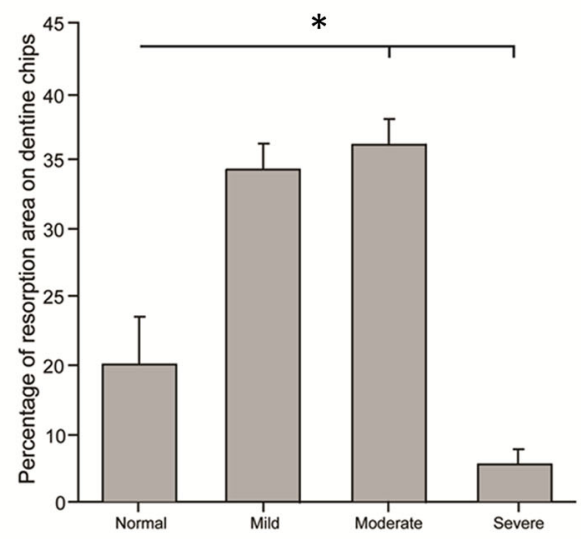

d

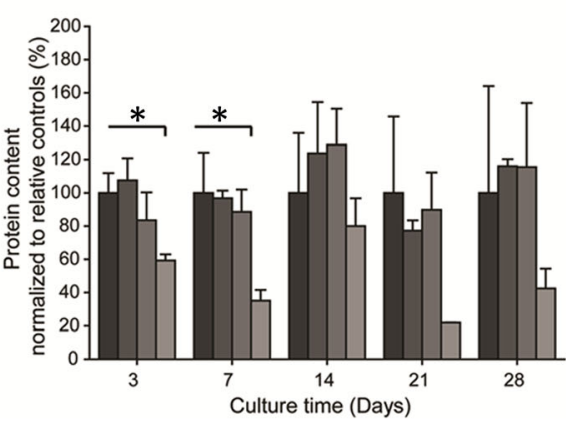

differences were also observable between the severe and mild/ moderate conditions. Regression analysis showed a significant linear correlation of $\mathrm{NaCl}$ concentration and the number of TRAP-positive osteoclasts $\left(R^{2}=0.9008 ; p<0.001\right)$ (Fig. $2 \mathrm{c}$ ), suggesting a concentration-dependent effect.

\section{CTR and CK immunocytochemistry}

As shown in Fig. 3a, b, elevation in $\mathrm{NaCl}$ concentration was found to increase the number of human CTR-positive cells and significant variation was detected between the severe and normal hypernatremia conditions (Fig. 3b). No fluorescent signal was detected in the negative controls. There was no statistically significant difference in the number of human CKpositive cells in the different treatment groups (Fig. 3c, d).

\section{Resorption assay}

Similar to TRAP and CTR staining observations, an increased $\mathrm{NaCl}$ concentration was associated with a significant and linear increase in human osteoclastic resorption area (Fig. 4). Osteoclastic resorbing activity significantly increased at the severe hypernatremia condition compared to the normal $/ \mathrm{mild} /$ moderate hypernatremia conditions (Fig. 4b). Regression analysis showed a significant linear correlation between $\mathrm{NaCl}$ concentration and resorption area $\left(R^{2}=0.8917 ; p<0.001\right)$ (Fig. $4 \mathrm{c}$ ).

The resorption activities of human osteoclasts were further analyzed by determining the resorption volume with a confocal laser scanning microscope. As shown in Fig. 5, both the shape and the size of individual resorption lacunae were highly variable in different hypernatremia conditions. The pits were smaller and shallower in normal $/ \mathrm{mild} /$ moderate hypernatremia conditions compared to those in the severe hypernatremia condition. A significant increase in resorption activity relative to the control condition was found for all (mild/moderate/severe) high-NaCl conditions (Fig. 5). The volume of dentin excavated by osteoclasts in severe hypernatremia cultures was 3.5 -fold higher compared to the control. Linear regression analysis showed a significant correlation between the resorption volume and the concentration of supplemented $\mathrm{NaCl}\left(R^{2}=0.9664 ; p<0.001\right)$ (Fig. 5c), suggesting a concentration-dependent effect.

\section{RT-PCR}

After 28 days of culturing, RT-PCR was performed to investigate the molecular mechanism for the effect of $\mathrm{NaCl}$ on human osteoclastogenesis. As shown in Fig. 6, when cells were treated with increasing concentrations of $\mathrm{NaCl}$, no significant difference was detected in the messenger RNA 
a
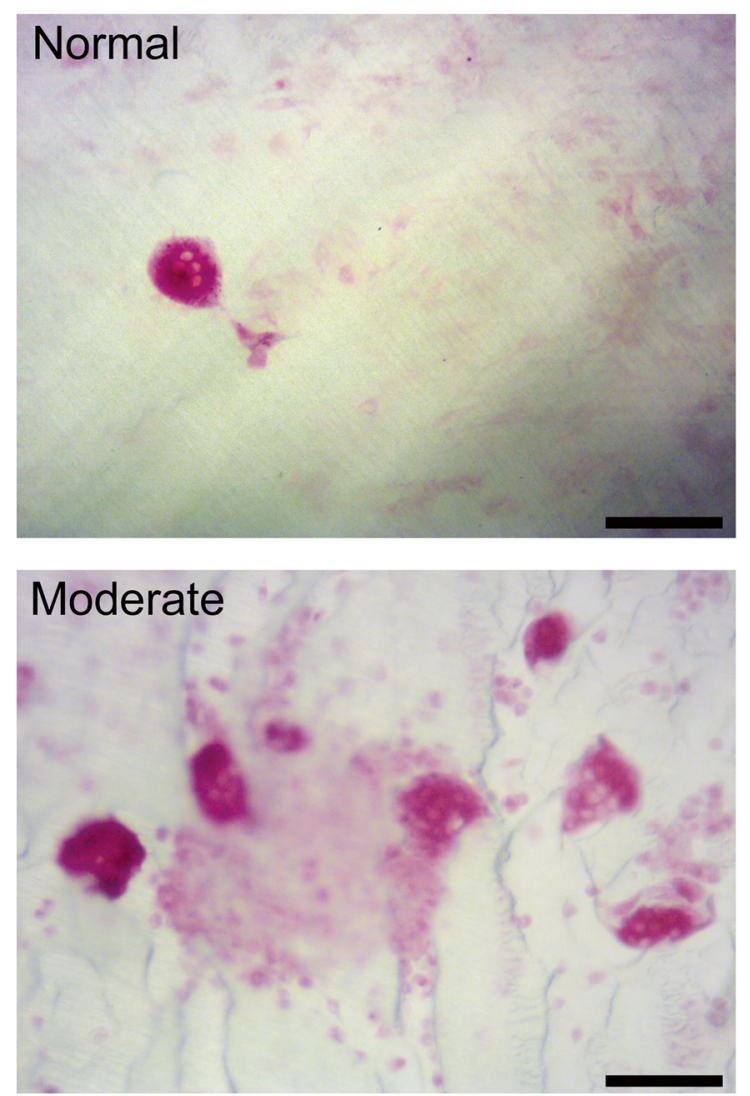

b

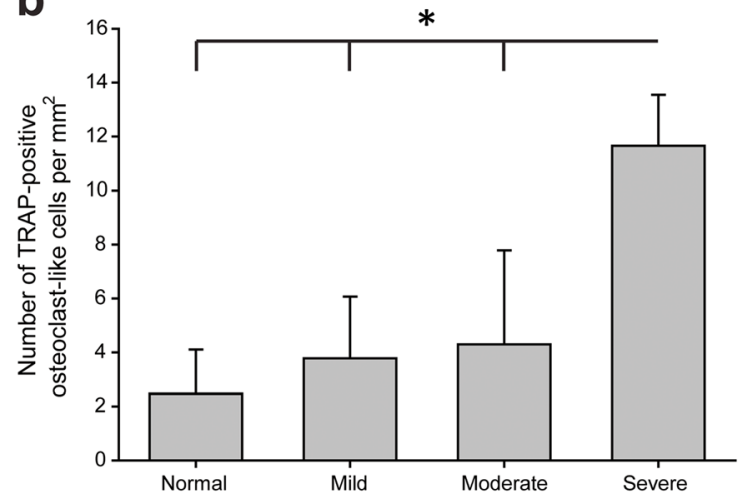

Fig. 2 TRAP-stained osteoclasts on dentin slices at d28. a Micrographs of TRAP-positive staining of multinucleated cells (biological triplicates for each $\mathrm{NaCl}$ condition). The scale bar represents $100 \mu \mathrm{m}$. The number of TRAP-positive cells per square millimeter (at least five representative

(mRNA) expressions for $C K, N F \kappa B 1, O S C A R$, and $R A N K$. For the mRNA expression analyses of osteoclastic-specific genes NFATcl and SPI1, significant differences were detected between the normal and severe hypernatremia conditions.

\section{Discussion}

We explored here the possibility of whether hypernatremia could have a direct influence on mouse and human osteoclasts
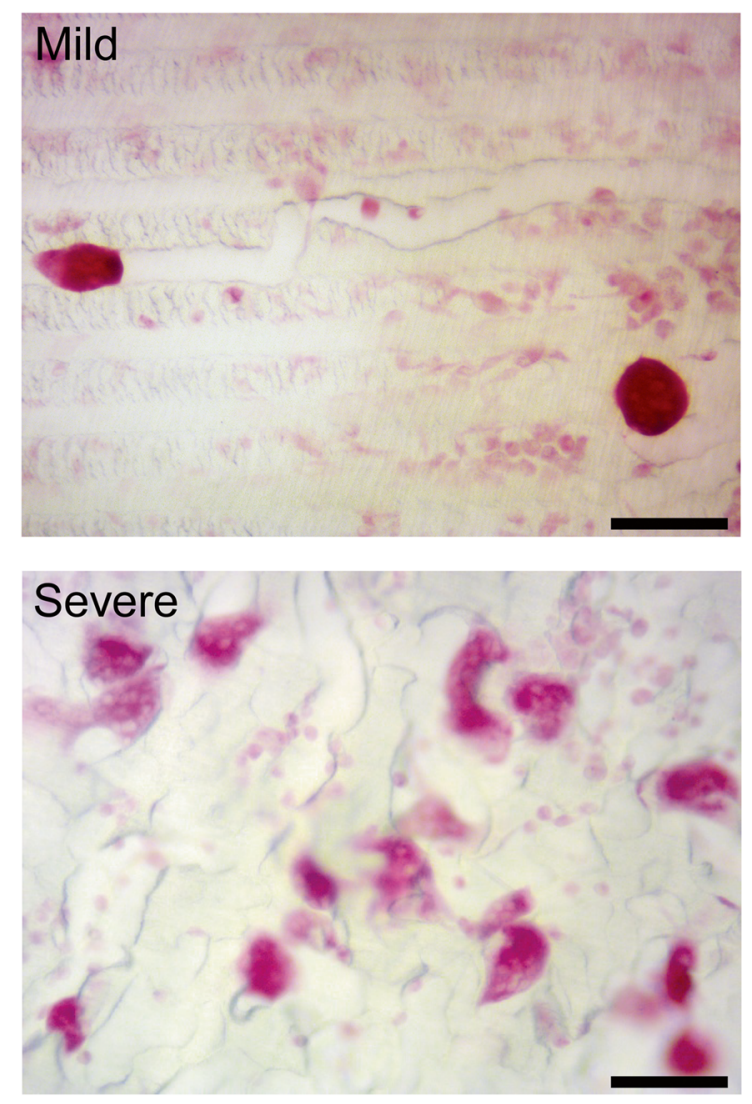

C

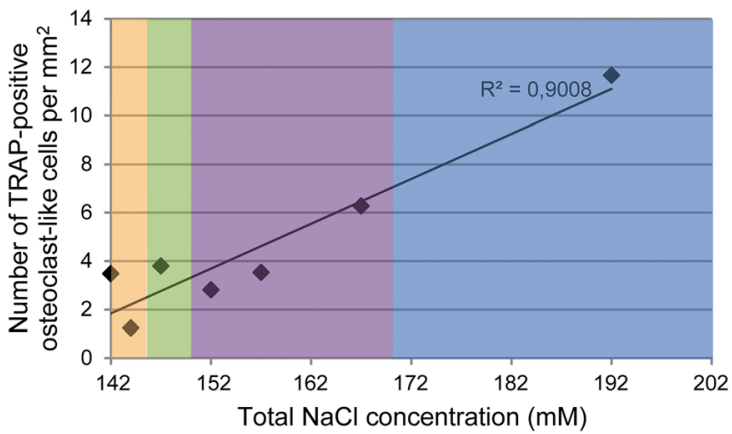

fields of view per condition) was recorded. b The respective statistical analyses are presented, and symbols represent the statistical significances between each group $(p<0.05)$. $\mathbf{c}$ Regression analysis suggesting a linear relationship with $R^{2}=0.901, p<0.001$

via an in vitro osteoclastogenesis model. A direct, progressive, and PTH-independent osteoclastogenic effect of hypernatremic culture conditions was demonstrated.

In the present study, the influence of different hypernatremia culture conditions on mouse osteoclastogenesis was first investigated. An increase in TRAP activity and osteoclastic resorption activity was found with the increase in the concentration of supplemented $\mathrm{NaCl}$ (maximum at the moderate hypernatremia condition). In the human system, the results were even more consistent. The cell metabolism 
a
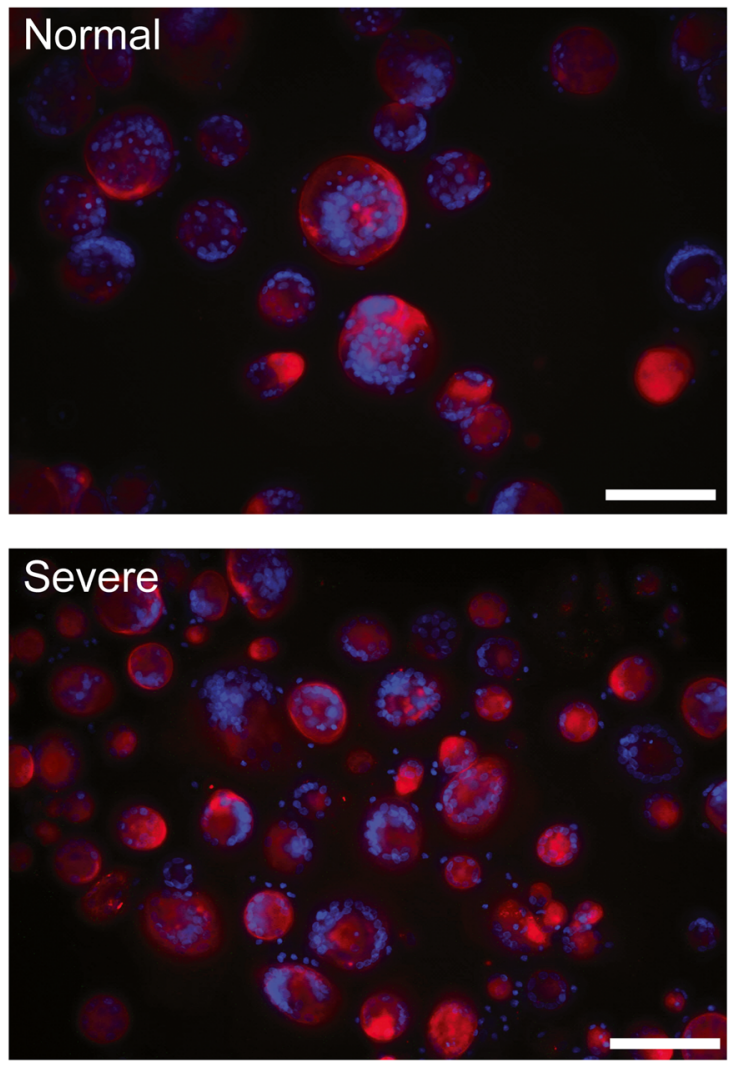

C
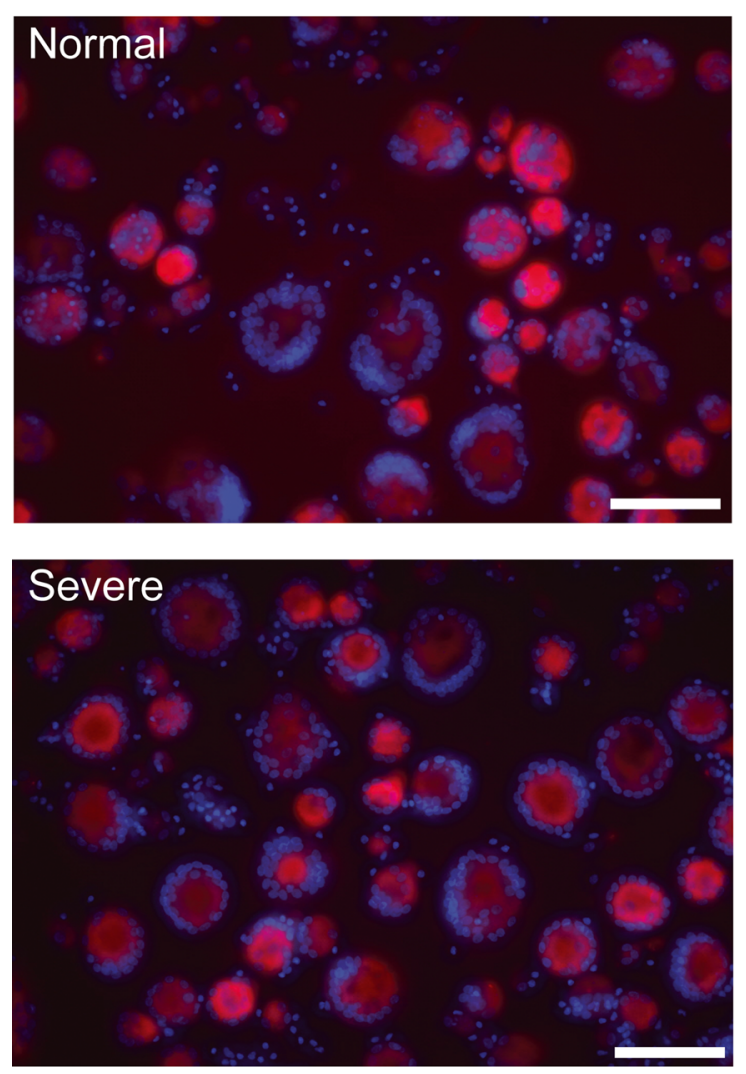
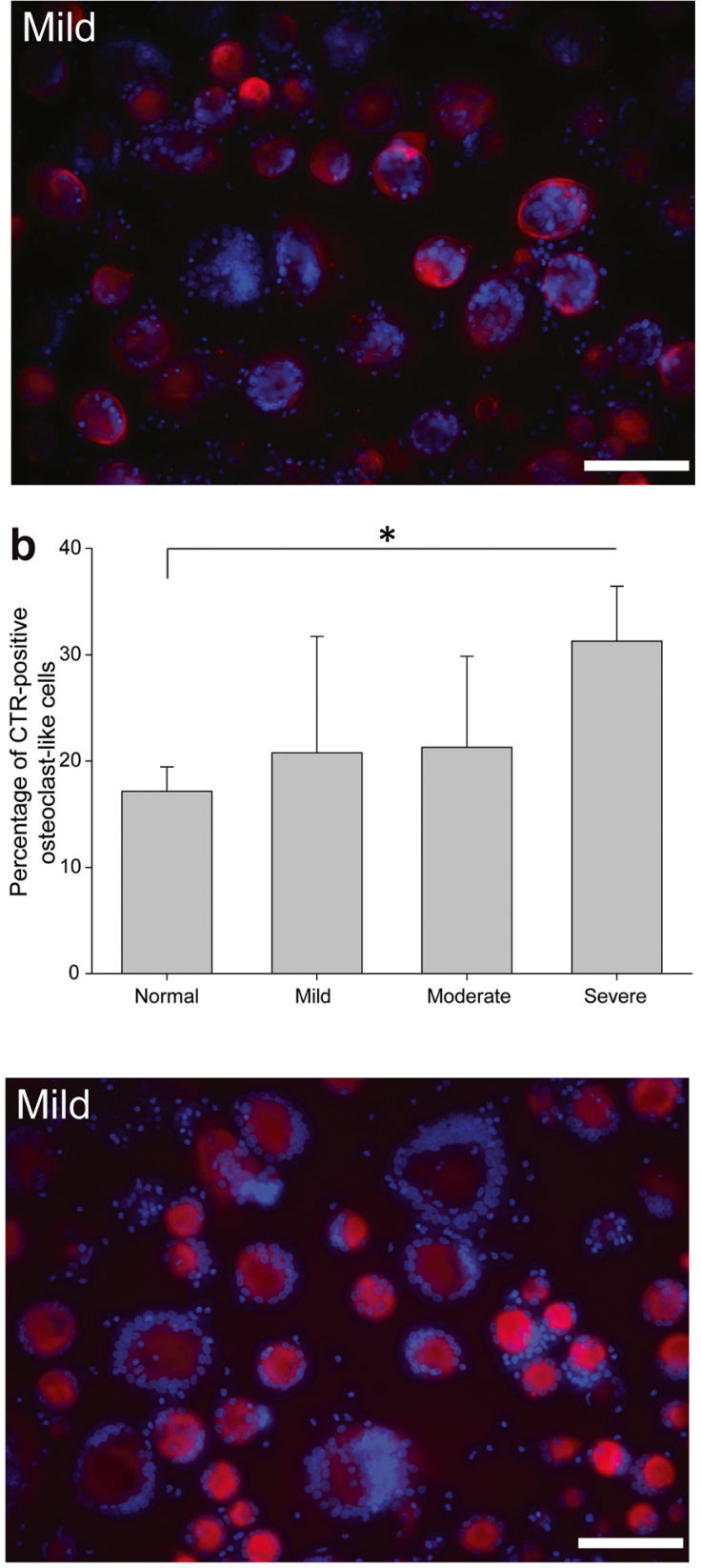

d

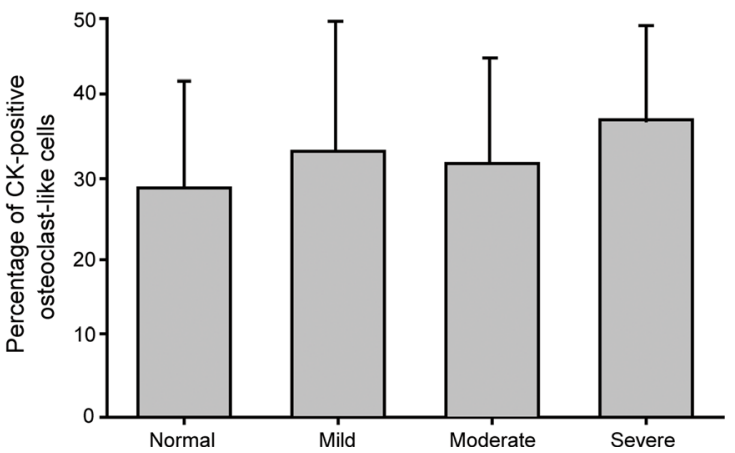


4 Fig. 3 Evidence of CTR and CK expressions in OCLs at day 28. a Micrographs of CTR staining (replicates per $\mathrm{NaCl}$ concentration). Scale ba $r=100 \mu \mathrm{m}$. b The means of the percentages of CTR-positive cells in the different culture conditions (at least five representative fields of view per condition). c Micrographs of CK staining (replicates per $\mathrm{NaCl}$ concentration). Scale bar $=100 \mu \mathrm{m}$. d The means of the percentages of CKpositive cells in the different culture conditions (at least five representative fields of view per condition). The respective statistical analyses are presented, and symbols indicate significant differences $(p<0.05)$

of PBMC-derived human osteoclast precursors and OCLs was then examined by WST-1 assay. We found an increase in metabolic activity of the cell combinations in the mild and moderate hypernatremia conditions. In the severe hypernatremia treatment, in comparison to the other groups including the control group, there was a strong downregulation at this concentration. This is consistent with a previous study in which C6 glioma cells from a rat were used and a reduction in the number of viable cells in a concentrationdependent manner was observed when exposed to high $\mathrm{NaCl}$ [26]. While most of the studies involved acute application of $\mathrm{NaCl}$ for only a few hours, the response of HeLa (human cervical epithelial carcinoma) cells and primary mouse embryonic fibroblasts to prolonged exposure to high $\mathrm{NaCl}$ (18 and 10 days, respectively) was investigated. It was reported that the rate of proliferation of the $\mathrm{NaCl}$-treated HeLa cells decreased gradually and the cells displayed signs of senescence while the appearance of cellular senescence in primary mouse embryonic fibroblasts was accelerated as well [27]. Inorganic ions or compatible osmolytes as well as their resultant osmolarity seem to act on cell protein synthesis. A number of recent studies have shown that protein synthesis in cells exposed to the hypertonic osmolarity of the extracellular medium was profoundly inhibited. By raising the osmolarity of the culture medium to $0.4 \mathrm{Osm} / \mathrm{L}$, Petronini et al. [28] showed a maximal inhibition of $50-60 \%$ protein synthesis in chick embryo fibroblasts within 30 min of treatment. Consistently, transient impairment of the rate of protein synthesis also occurred in cultured endothelial cells [29]. In our results presented here (Fig. 1d), the total protein content production in the severe hypernatremia group was also impaired at all the time points, suggesting an inhibition of cell metabolism and protein production in our culture system with high concentration of $\mathrm{NaCl}$. Compared to day 3, there, however, still was a modest increase in both values detected at day 28 , ruling out the general toxicity of a high concentration. Interestingly, even though there was a relatively lower overall cell activity in the severe group compared to the other groups at the same time point, we found more active osteoclasts there than in any other group suggesting diverging effects of increased $\mathrm{NaCl}$ concentrations on the mixed cell population at different stages of differentiation. A possible explanation for these data would be that increasing concentrations of $\mathrm{NaCl}$ favor osteoclast differentiation over proliferation of precursor cells, leading to a higher relative number of multinucleated osteoclasts. Indeed, when we analyzed the number of TRAP-positive multinucleated cells, a linear relationship was found between the number of osteoclast-like TRAP-positive multinuclear cells per square millimeter and the concentration of supplemented $\mathrm{NaCl}$ (Fig. $2 ; R^{2}=0.9008, p<0.001$ ). This indicates an inductive effect of hypernatremic conditions on the formation of human bone-resorbing osteoclasts. Similar results were obtained for the CTR expression (Fig. 3).

While multinucleation and specific protein expression suggest the development of osteoclasts, their most important property is the resorption activity. We have performed 2D resorption area measurement and $3 \mathrm{D}$ resorption volume evaluation, which enable deeper analysis of the influence of a high concentration of $\mathrm{NaCl}$ on osteoclastic function. A well-fit linear correlation between the resorption capacity (in terms of resorption area and volume) and the $\mathrm{NaCl}$ concentration was found with $R^{2}=0.8917$ (Fig. 4) and 0.9664, respectively (Fig. $5)$, suggesting a direct, activating effect of hypernatremic conditions on the function of human osteoclasts. In order to further study the mechanism of the significantly enhanced bone resorption in different hypernatremia conditions, we determined the relative resorption of a single osteoclast by normalizing the percentage of the resorbed area by the number of TRAP-positive cells. We found a decrease in single-cell resorption in hypernatremia condition (data not shown), suggesting that the observed effect is mainly due to the increased numbers of osteoclasts and not the increased resorption activity by an individual cell. However, as this is an endpoint analysis (day 28), it is difficult to distinguish the effects of various hypernatremia conditions on different phases in a mixed cell population. To rule out the effect on a single osteoclast, additional experiments with freshly reseeded osteoclasts under different $\mathrm{NaCl}$ conditions would be necessary. Our results, however, clearly indicated an increase in $\mathrm{NaCl}$-induced bone resorption in a direct, cell-mediated fashion without regulation by PTH.

To elucidate the molecular mechanism of NaCl's stimulatory effects on osteoclast formation and function, we analyzed the mRNA levels of the genes during osteoclastogenesis in the exposure to different hypernatremia conditions. Among the many genes related to osteoclast differentiation, the mRNA levels of NFATC1 and SPI1, master transcription factors for osteoclastogenesis, were significantly increased (Fig. 6). It is widely accepted that M-CSF and RANKL released by osteoblasts are the two key cytokines that are essential and sufficient for the differentiation of osteoclasts from the monocyte/ macrophage lineage. The binding of M-CSF to its receptor (colony-stimulating factor 1 receptor or c-Fms) will activate the survival and proliferation of osteoclast precursor cells and the RANK expression, evoking efficient response to the RANKL-RANK signaling pathways. The RANKL-RANK 
interaction will in turn trigger a sequence of events that leads to the activation of various downstream transcription factors, such as NFKB and the expression of the master regulators for osteoclast differentiation, i.e., NFATC1 and SPI1 [30]. In particular, NFATCl is considered to be the transcription factor that is most strongly induced by RANKL [31]. Interestingly, we did not see a parallel increase in $C K, N F \kappa B 1, O S C A R$, and $R A N K$ in our analyses. This might be caused by the poor correlation between gene expression and protein levels. Vogel and Marcotte [32] have reviewed that since there are many processes between cellular transcription and translation, changes in gene expression level are frequently not reflected at a
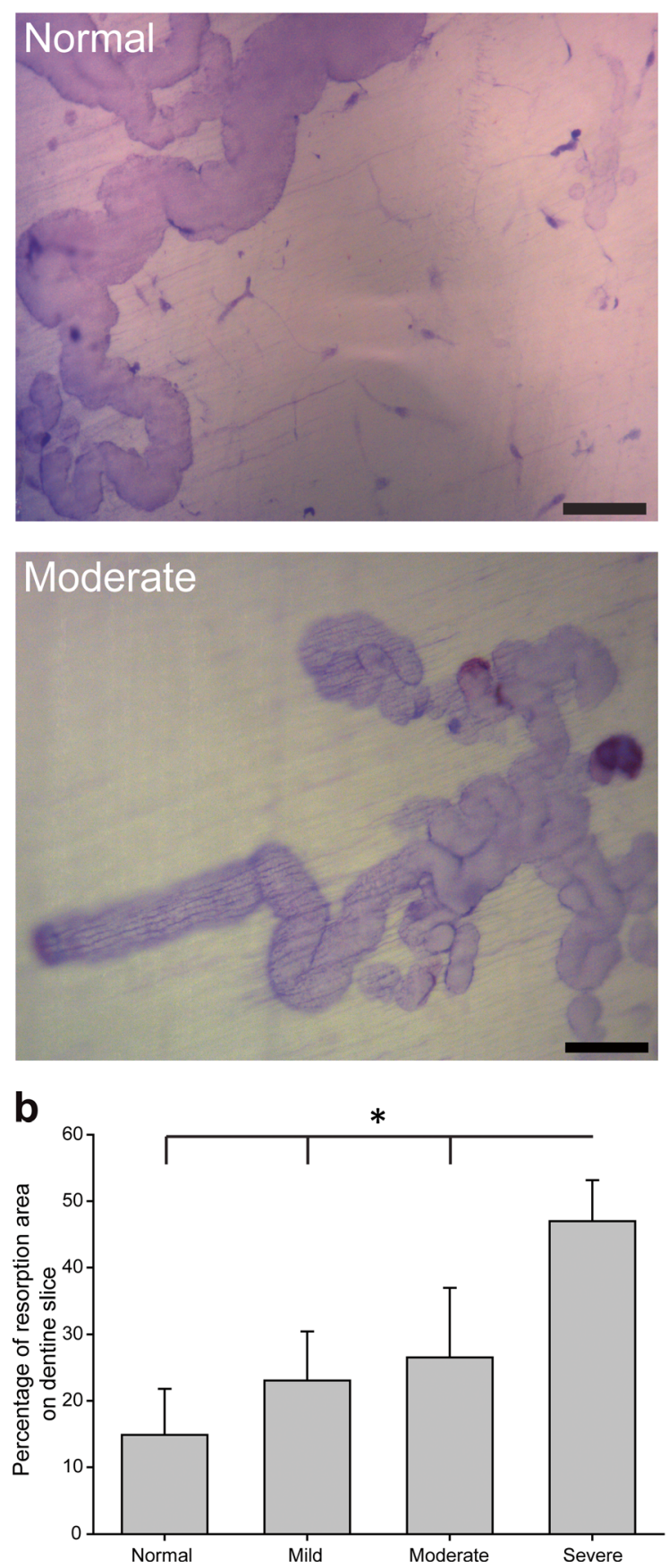

Fig. 4 2D resorption assay at day 28. a Micrographs of osteoclastic 2D resorption area (by toluidine blue staining; at least three chips per condition). Scale bar $=200 \mu \mathrm{m}$. b The osteoclastic resorption area was determined and presented as the means of the percentages of resorption
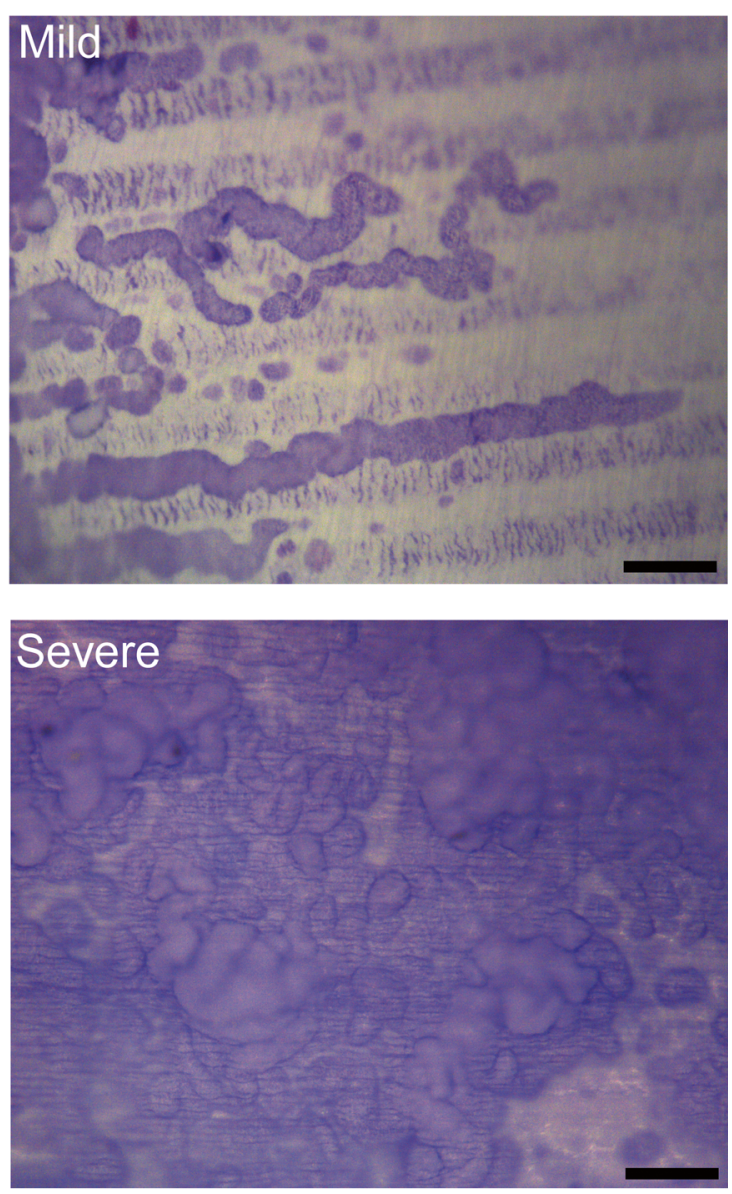

C

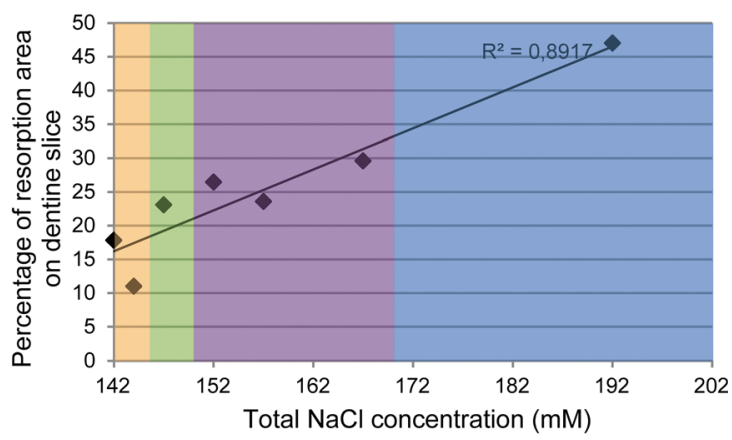

area in at least five representative fields of view per condition. The respective statistical analyses are presented, and symbols indicate significant differences $(p<0.05)$. c A positive linear correlation was confirmed in the regression analysis with $R^{2}=0.892 ; p<0.001$ 
a
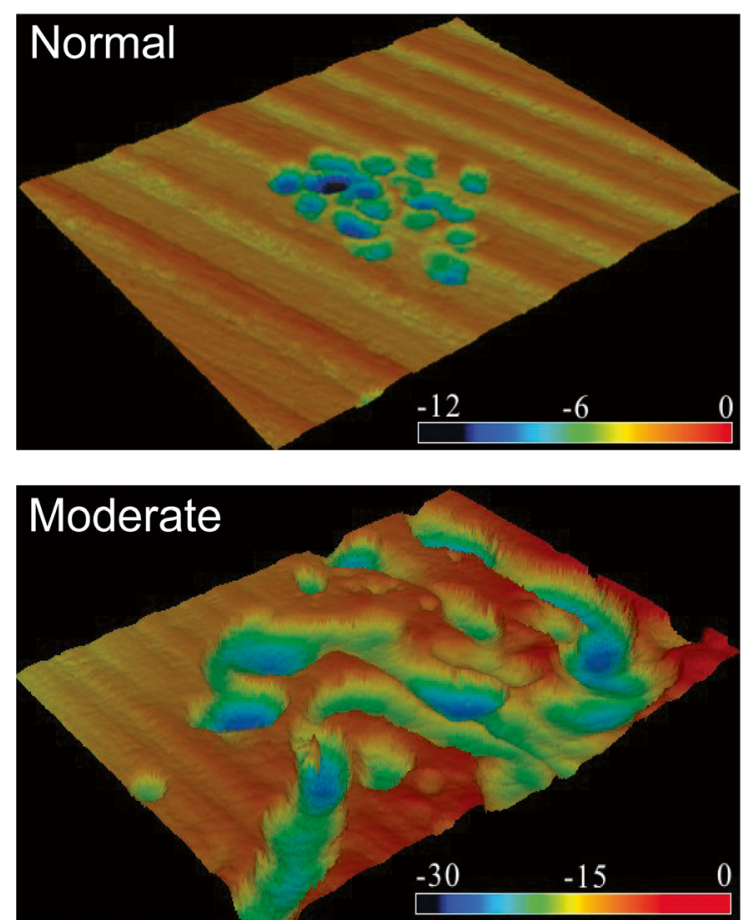

b

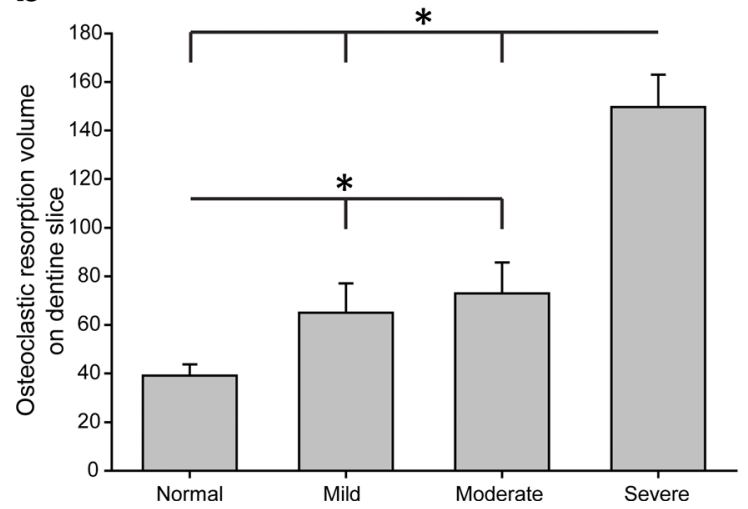

Fig. 5 Effect of $\mathrm{NaCl}$ on bone-resorbing volume assessed by $3 \mathrm{D}$ analysis using confocal laser scanning microscopy. a Topographical views of resorption pits from randomly chosen sites in dentin slices (at least three chips per condition) produced by color 3D profile confocal laser microscope. Color contours represent the different depths of the resorption pits in the vertical direction (black, deep; red, shallow; $\mu \mathrm{m}$ ). b Resorbed

the protein level (the correlation can be as little as $40 \%$ ). The transcriptional level data in this study can only suggest whether or not the protein is present. However, it has been highly confirmed that there is an increase both in the TRAP-positive OCL formation and in the 2D and 3D resorptive data in the culture with the highest concentration of $\mathrm{NaCl}$. While the present study demonstrates a direct relationship between hypernatremia and mouse/human osteoclastic resorption activity, it does not completely exclude the possibility that factors associated with hypernatremia, such as a higher extracellular osmolality, can play a role on osteoclastogenesis. It has
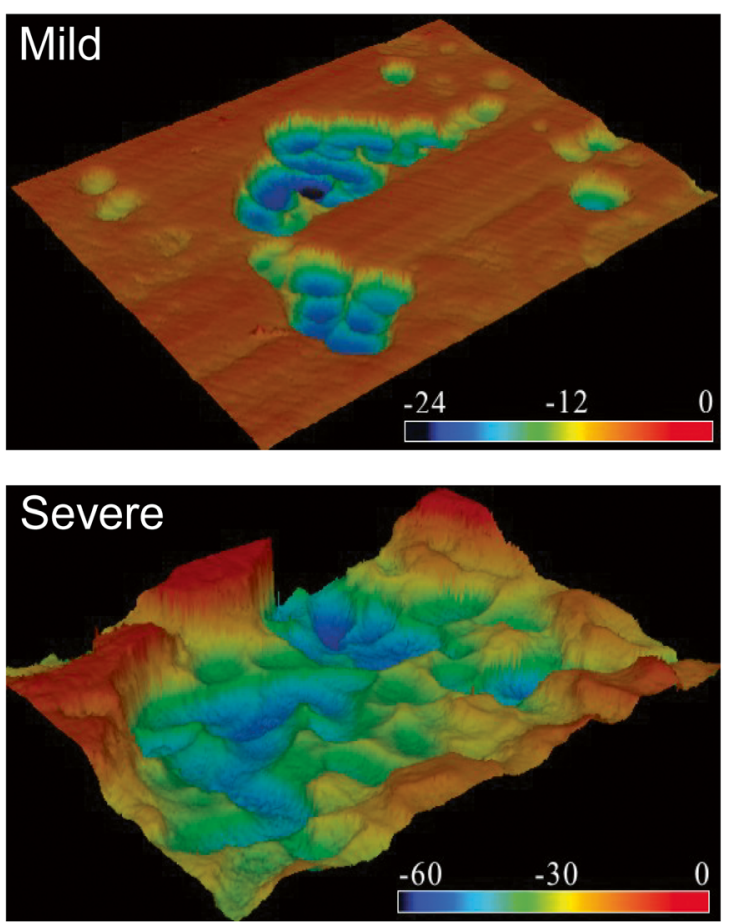

C

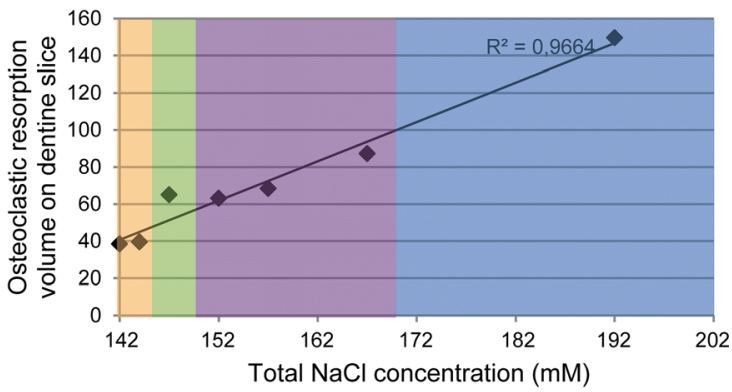

volume of the pits was determined using VK Analyzer image analyzing software (at least five representative fields of view per condition). The respective statistical analyses are presented, and symbols indicate significant differences $(p<0.05)$. c The regression analysis indicates a linear correlation between the resorption volume and the concentration of supplemented $\mathrm{NaCl}$ with $R^{2}=0.966, p<0.001$ (color figure online)

been demonstrated that changes in extracellular osmolality might induce cell swelling which activates stretch- and swelling-activated cation channels. The activation of the calcium channels thus leads to the increase in calcium influx and intracellular calcium. This might influence osteoclastic behavior through promoting osteoclast apoptosis and inhibiting osteoclastic bone resorption [33]. However, in our previous work, we did not observe the effect of changes in osmolality through $\mathrm{Mg}^{2+}$ [34]. It suggests that it is $\mathrm{NaCl}$ rather than the resultant high extracellular osmolality that induces osteoclastogenesis. In other words, if the negative role of the osmolality 


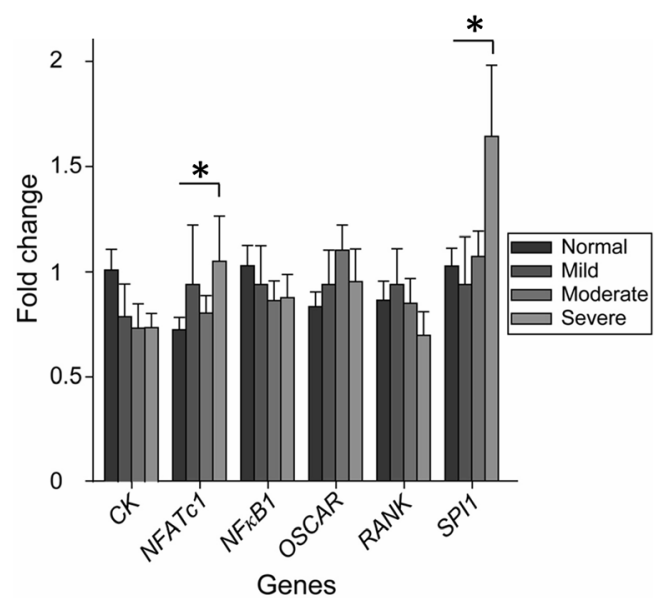

Fig. 6 Determination of the mRNA expression of osteoclastic-specific genes in the cultures exposed to different hypernatremia conditions. Expression of markers is normalized to that of reference genes actin $\beta$, $B 2 M, G A P D H$, and RPL10. Symbols indicate significant differences between normal group and other hypernatremia conditions $(p<0.05)$

exists, it might be abolished by the strong effects of $\mathrm{NaCl}$ on osteoclastogenesis. Using cellular and molecular approaches, Barsony et al. [6] suggested as well that it is the medium $\mathrm{Na}^{+}$ level rather than the resultant osmolality that changed osteoclast formation and resorption activity in experiments with a low concentration of $\mathrm{NaCl}$. Similar mechanisms could also act at higher concentrations of $\mathrm{Na}^{+}$. An important question is how osteoclasts sense increased extracellular $\mathrm{Na}^{+}$concentration. Voltage-gated $\mathrm{Na}$ channels were suggested to function as $\mathrm{Na}$ sensors in the bone [35]. Interestingly, assays on murine preosteoclastic RAW 264.7 cells and on primary marrow monocytes both suggested that hyponatremia could be associated with osteoporosis [6]. However, there is inconclusive evidence on the effect of hyponatremia on the development of osteoporosis in human patients [36]. Hyponatremia seems to directly contribute to increased bone resorption through decreased cellular uptake of ascorbic acid and the induction of oxidative stress [37]. Furthermore, it has been investigated that hyponatremic patients have elevated circulating levels of arginine vasopressin (AVP) and that this is at least in part responsible for the phenotype [38]. As AVP is also increased with dehydration in hyperosmolar hypernatremia, it may influence bone remodeling with a similar mode of action.

Nevertheless, hypernatremia may lead to the activation of osteoclasts through another completely different pathway. One possible route may be an exchange of calcium and sodium through sodium/calcium exchanger (NCX) family like NCX1 which has been revealed to act as a regulator of osteoclast-mediated bone resorption [39]. An increased extracellular level of sodium might lead to the depletion of intracellular calcium through these exchangers and consequently to the increase of their resorptive function. In the present study, since we were mainly interested in the human diseases, the effect of hypernatremia on osteoclastogenesis was therefore primarily investigated in a human cell culture system. Instead of a PTH-dependent role of high salt intake on bone resorption, a direct, cell-mediated effect of hypernatremic conditions on human osteoclastogenesis was shown. In order to test whether the regulation pattern of osteoclastogenesis by increased concentrations of $\mathrm{NaCl}$ also applies to other species, the effects of different hypernatremia conditions on osteoclastogenesis derived from murine bone marrow macrophages were also investigated as an alternative system. Also, in the murine cells, we found an increased resorption area at moderately elevated concentrations of $\mathrm{NaCl}$, suggesting a conserved mechanism. At severely high concentrations of $\mathrm{Na}$, the mouse cells were overall impaired, while the human cells were further stimulated. The laboratory mouse provides an attractive mammalian model due to its ease of genetic manipulation. However, Rangarajan and Weinberg reviewed that there are fundamental differences between the two species [40]. Furthermore, differences between human and mouse embryonic stem cells were reported to be species-specific rather than arising from differences in culturing conditions [41].

Severe hypernatremia has been described in various case reports, as high as a serum $\mathrm{Na}^{+}$concentration of 185 [42], 195 [43], or even $255 \mathrm{mM}$ [44]. In those cases, compared with other multiple pathologies (like metabolic acidosis and severe neurological impairment) caused by an extremely high $\mathrm{Na}^{+}$concentration, the increase in the generation of osteoclast would probably be a minor concern. However, our finding that bone resorption has already increased significantly at medium $\mathrm{NaCl}$ concentrations suggests that it may be important for bone physiology.

\section{Conclusion}

Taken together, our data suggests that mouse/human osteoclastic differentiation and function are directly and positively regulated by $\mathrm{NaCl}$ concentrations over the physiologic $142 \mathrm{mM}$. Therefore, the reported increased bone resorption after diets rich in $\mathrm{NaCl}$ and in diseases with changes in water balance leading to high serum $\mathrm{Na}^{+}$may not only be secondary to the urinary loss of calcium but may also be due to a direct, cell-mediated effect of increased $\mathrm{Na}^{+}$concentration on osteoclasts. This may be especially important, as dehydration also leads to increased $\mathrm{NaCl}$ concentration in the body and therefore around bone cells. Especially old people are known to lose the appropriate thirst to balance their water intake. Furthermore, if $\mathrm{NaCl}$ directly increases osteoclastic resorption, patients with a dysbalance of the $\mathrm{NaCl}$ metabolism might show stronger response to anti-resorptive treatment. 
These findings may help to explain clinical findings on bone metabolism in patients with increased serum concentrations of $\mathrm{NaCl}$.

Acknowledgements Sincerest gratitude to all the colleagues from the Department of Plastic Surgery and Hand Surgery, Technical University Munich; the Department for Biological Characterization, HelmholtzZentrum Geesthacht; and the Heisenberg-Group for Molecular Skeletal Biology, Department of Trauma, Hand, and Reconstructive Surgery, University Medical Center Hamburg-Eppendorf, for their generous guidance and contribution to the great work atmosphere.

Compliance with ethical standards Buffy coats were obtained from healthy, anonymized donors at the Institute for Clinical Transfusion Medicine and Immunogenesis Ulm, Ulm, Germany, in a procedure approved by the review board of the German National Advisory Committee Blood at the Robert Koch Institute. All donors provided written consent that their cells can be used for medical, scientific, and pharmaceutical purposes.

Funding The studies reported in this publication were supported by the financial funding from the China Scholarship Council and the Helmholtz Association.

\section{Conflicts of interest None.}

Open Access This article is distributed under the terms of the Creative Commons Attribution-NonCommercial 4.0 International License (http:// creativecommons.org/licenses/by-nc/4.0/), which permits any noncommercial use, distribution, and reproduction in any medium, provided you give appropriate credit to the original author(s) and the source, provide a link to the Creative Commons license, and indicate if changes were made.

\section{References}

1. Ivaska KK, Gerdhem P, Väänänen HK, Åkesson K, Obrant KJ (2010) Bone turnover markers and prediction of fracture: a prospective follow-up study of 1040 elderly women for a mean of 9 years. $\mathrm{J}$ Bone Miner Res 25:393-403

2. Kanis J, Johnell O (2005) Requirements for DXA for the management of osteoporosis in Europe. Osteoporos Int 16:229-238

3. Dimitri P, Wales JK, Bishop N (2010) Fat and bone in children: differential effects of obesity on bone size and mass according to fracture history. J Bone Miner Res 25:527-536

4. McGuigan FE, Murray L, Gallagher A, Davey-Smith G, Neville CE, Van't Hof R, Boreham C, Ralston SH (2002) Genetic and environmental determinants of peak bone mass in young men and women. J Bone Miner Res 17:1273-1279

5. Prynne CJ, Mishra GD, O'Connell MA, Muniz G, Laskey MA, Yan L, Prentice A, Ginty F (2006) Fruit and vegetable intakes and bone mineral status: a cross sectional study in 5 age and sex cohorts. Am J Clin Nutr 83:1420-1428

6. Barsony J, Sugimura Y, Verbalis JG (2011) Osteoclast response to low extracellular sodium and the mechanism of hyponatremiainduced bone loss. J Biol Chem 286:10864-10875

7. Verbalis JG, Barsony J, Sugimura Y, Tian Y, Adams DJ, Carter EA, Resnick HE (2010) Hyponatremia-induced osteoporosis. J Bone Miner Res 25:554-563
8. Devine A, Criddle RA, Dick IM, Kerr DA, Prince RL (1995) A longitudinal study of the effect of sodium and calcium intakes on regional bone density in postmenopausal women. Am J Clin Nutr 62:740-745

9. Harrington M, Cashman KD (2003) High salt intake appears to increase bone resorption in postmenopausal women but high potassium intake ameliorates this adverse effect. Nutr Rev 61:179-183

10. Goulding A, Campbell D (1983) Effects of oral loads of sodium chloride on bone composition in growing rats consuming ample dietary calcium. Miner Electrolyte Metab 10:58-62

11. Need AG, Morris HA, Cleghorn DB, De Nichilo D, Horowitz M, Nordin B (1991) Effect of salt restriction on urine hydroxyproline excretion in postmenopausal women. Arch Intern Med 151:757

12. Itoh R, Suyama Y (1996) Sodium excretion in relation to calcium and hydroxyproline excretion in a healthy Japanese population. Am J Clin Nutr 63:735-740

13. Chan EL, Swaminathan R (1994) The effect of high protein and high salt intake for 4 months on calcium and hydroxyproline excretion in normal and oophorectomized rats. J Lab Clin Med $124: 37-41$

14. MacGregor GA (1997) Salt—more adverse effects. Am J Hypertens 10:37S-41S

15. Lin P-H, Ginty F, Appel LJ, Aickin M, Bohannon A, Garnero P, Barclay D, Svetkey LP (2003) The DASH diet and sodium reduction improve markers of bone turnover and calcium metabolism in adults. J Nutr 133:3130-3136

16. Aub JC, Tibbetts DM, McLean R (1937) The influence of parathyroid hormone, urea, sodium chloride, fat and of intestinal activity upon calcium balance. J Nutr 13:635-655

17. Chan EL-P, Swaminathan R (1998) Calcium metabolism and bone calcium content in normal and oophorectomized rats consuming various levels of saline for 12 months. J Nutr 128:633-639

18. Ginty F, Flynn A, Cashman KD (1998) The effect of dietary sodium intake on biochemical markers of bone metabolism in young women. Br J Nutr 79:343-350

19. Peacock M (2010) Calcium metabolism in health and disease. Clin J Am Soc Nephrol 5:S23-S30

20. Teucher B, Dainty JR, Spinks CA, Majsak-Newman G, Berry DJ, Hoogewerff JA, Foxall RJ, Jakobsen J, Cashman KD, Flynn A (2008) Sodium and bone health: impact of moderately high and low salt intakes on calcium metabolism in postmenopausal women. J Bone Miner Res 23:1477-1485

21. Goulding A (1980) Effects of dietary $\mathrm{NaCl}$ supplements on parathyroid function, bone turnover and bone-composition in rats taking restricted amounts of calcium. Miner Electrolyte Metab 4:203-208

22. Breslau NA, Mcguire JL, ZERWEKH JE, PAK CY (1982) The role of dietary sodium on renal excretion and intestinal absorption of calcium and on vitamin D metabolism. J Clin Endocrinol Metab 55: 369-373

23. Elder G (2002) Pathophysiology and recent advances in the management of renal osteodystrophy. J Bone Miner Res 17:2094-2105

24. Clinical Practice Guidelines-Hypernatremia. The Royal Children's Hospital Melbourne. http://www.rch.org.au/clinicalguide/ guideline_index/Hypernatraemia/. Accessed 6 July

25. Schilling AF, Linhart W, Filke S, Gebauer M, Schinke T, Rueger JM, Amling M (2004) Resorbability of bone substitute biomaterials by human osteoclasts. Biomaterials 25:3963-3972

26. Arimochi H, Morita K (2005) High salt culture conditions suppress proliferation of rat $\mathrm{C} 6$ glioma cell by arresting cell-cycle progression at S-phase. J Mol Neurosci 27:293-302

27. Dmitrieva NI, Burg MB (2007) High $\mathrm{NaCl}$ promotes cellular senescence. Cell Cycle-Landes Biosci 6:3108

28. Petronini PG, Tramacere M, Kay JE, Borghetti AF (1986) Adaptive response of cultured fibroblasts to hyperosmolarity. Exp Cell Res $165: 180-190$ 
29. Petronini PG, Alfieri RR, Losio MN, Caccamo AE, Cavazzoni A, Bonelli MA, Borghetti AF, Wheeler KP (2000) Induction of BGT-1 and amino acid system a transport activities in endothelial cells exposed to hyperosmolarity. Am J Phys Regul Integr Comp Phys 279:R1580-R1589

30. Kim JH, Kim N (2014) Regulation of NFATc1 in osteoclast differentiation. J Bone Metab 21:233-241

31. Takayanagi H, Kim S, Koga T, Nishina H, Isshiki M, Yoshida H, Saiura A, Isobe M, Yokochi T, J-i I (2002) Induction and activation of the transcription factor NFATc1 (NFAT2) integrate RANKL signaling in terminal differentiation of osteoclasts. Dev Cell 3:889901

32. Vogel C, Marcotte EM (2012) Insights into the regulation of protein abundance from proteomic and transcriptomic analyses. Nat Rev Genet 13(4):227-232

33. Shen B, Wong CO, Lau OC, Woo T, Bai S, Huang Y, Yao X (2015) Plasma membrane mechanical stress activates TRPC5 channels. PLoS One 10(4):e0122227

34. Wu L, Luthringe BJC, Feyerabend F, Schilling AF, Willumeit R (2014) Effects of extracellular magnesium on the differentiation and function of human osteoclasts. Acta Biomater 10:2843-2854

35. Marban E, Yamagishi T, Tomaselli GF (1998) Structure and function of voltage-gated sodium channels. J Physiol 508:647-665

36. Ayus JC, Negri AL, Kalantar-Zadeh K, Moritz ML (2012) Is chronic hyponatremia a novel risk factor for hip fracture in the elderly? Nephrol Dial Transplant 27:3725-3731

37. Negri AL, Ayus JC (2017) Hyponatremia and bone disease. Rev Endocr Metab Disord 18(1):67-78
38. Tamma R, Sun L, Cuscito C, Lu P, Corcelli M, Li J, Colaianni G, Moonga SS, Di Benedetto A, Grano M, Colucci S, Yuen T, New MI, Zallone A, Zaidi M (2013) Regulation of bone remodeling by vasopressin explains the bone loss in hyponatremia. Proc Natl Acad Sci USA 110(46):18644-18649

39. Albano G, Dolder S, Siegrist M, Mercier-Zuber A, Auberson M, Stoudmann C, Hofstetter W, Bonny O, Fuster DG (2017) Increased bone resorption by osteoclast-specific deletion of the sodium/calcium exchanger isoform 1 (NCX1). Pflugers Arch 469(2):225-233

40. Rangarajan A, Weinberg RA (2003) Comparative biology of mouse versus human cells: modelling human cancer in mice. Nat Rev Cancer 3:952-959

41. Ginis I, Luo Y, Miura T, Thies S, Brandenberger R, Gerecht-Nir S, Amit M, Hoke A, Carpenter MK, Itskovitz-Eldor J (2004) Differences between human and mouse embryonic stem cells. Dev Biol 269:360-380

42. McGouran R (1975) Case of salt overdosage. BMJ 4:386-386

43. Choi S-S, Kim WY, Kim W, Lim K-S (2012) Unexpected fatal hypernatremia after successful cardiopulmonary resuscitation with therapeutic hypothermia: a case report. J Korean Med Sci 27:329-331

44. Ofran Y, Lavi D, Opher D, Weiss T, Elinav E (2004) Fatal voluntary salt intake resulting in the highest ever documented sodium plasma level in adults $\left(255 \mathrm{mmol} \mathrm{L}^{-1}\right)$ : a disorder linked to female gender and psychiatric disorders. J Intern Med 256:525-528 